\title{
Factors Associated with Treatment Compliance among Tuberculosis Patients Receiving Directly Observed Treatment Short Course Therapy
}

\author{
${ }^{1}$ Sunita Sharma, ${ }^{2}$ Neeta Tamrakar \\ ${ }^{1}$ School of Health and Allied Sciences, Pokhara University, Kaski, Nepal. \\ ${ }^{2}$ Pokhara Nursing Campus, Tribhuvan University, Kaski, Nepal.
}

\begin{abstract}
Tubercular infection is still a pervasive public health problem in Nepal despite the massive efforts of National Health Service stakeholders. This study was carried out to identify the factors associated with treatment compliance among Tuberculosis Patients Receiving DOTS in 11 centres of Pokhara valley. A cross-sectional descriptive study design was used to collect information from 142 Tuberculosis patients. Purposive sampling method was used and chi-square test was used at 5\% level of significance. Pattern of compliance was categorized as; compliance and non-compliance. Out of 142 respondents, majority (94.37\%) of respondents was compliant and minority (5.63\%) was non-compliant. Among non-compliant patients, (75.0\%) of respondents missed their medicine in intensive phase and the reasons for non-compliance were carelessness of patients, forgetfulness of patients, confusion of staff, side effects of medicines and agitation by political parties. The study found no significant association of treatment compliance with demographic factors, patient related factors, health service factors and social factors ( $p>0.05)$. The finding was satisfactory that the compliance of TB patients was high i.e. $(94.37 \%)$ of respondents were compliant. About (6.00\%) of respondents were non-compliant. The reasons for non-compliance were due to their own cause rather than health service factors. They themselves were responsible for being non-compliant. Tuberculosis, being a major public health problem; six percent non-compliance is still a serious health problem and being non-compliant; these patients can transmit tuberculosis to many other healthy people in the family and community. Therefore, tuberculosis patients should be more conscious on treatment compliance to improve their health as well as of family and community.
\end{abstract}

Key words: Compliance, non-compliance, DOTS Therapy

Corresponding address: Sunita Sharma, School of Health and Allied Sciences, Pokhara University, Kaski, Nepal. E-mail: sharmasunu789@gmail.com

\section{INTRODUCTION}

Tuberculosis (TB) is one of the main reasons of mortality and morbidity globally and it kills about two million people annually. In 2012, an estimate 8.6 million people developed TB and 1.3 million died from the disease. Of the estimated 8.6 million new TB cases worldwide in 2012, 5.7 million were male and 2.9 million were women. ${ }^{1}$

About 45 percent of total population in Nepal is estimated to be infected with TB, out of which 60 percent are in adult age group. Every year 40,000 people develop active TB, of them 20,000 have infectious pulmonary (smear positive) disease and 5000-7000 people still die per year from TB in Nepal. ${ }^{2}$ Compliance to TB treatment continues to be one of the major obstacles that TB control programmes worldwide have to deal with, especially in developing countries. Directly Observed Treatment Short course has been associated with reduced rate of treatment failure, relapse and drug resistance. However its impact in reducing TB incidence has been limited by non-compliance to Directly Observed Treatment Short Course which occurs when patients do not turn up for treatment at health facility or community DOTS point. $^{3}$

According to study done in Palpa District, among
101 respondents, more than one third $(38.60 \%)$ of TB patient were non-compliant. Majority $(79.50 \%)$ of the noncompliant patients had interrupted their treatment during the continuation phase. The major reasons for treatment interruption were side effects of drugs and feeling of betterment after the treatment. ${ }^{4}$

Tuberculosis treatment requires long duration of drug administration. By virtue of this, patients find it difficult to complete treatment most especially when they feel relieved after taking medication for the first two months of treatment. Poor adherence to prescribed medication increases the risk of morbidity, mortality and spread of disease in the community. Poor adherence to anti-TB medication is a major barrier to global TB control. ${ }^{5}$

According to a study done in Banke district, overall compliance to DOTS was $(86.80 \%)$. Among them, $(57.00 \%)$ showed excellent compliance, $(30.00 \%)$ good compliance and (13.20\%) participants were non complaint to DOTS therapy. High bacterial infectivity, transmissibility, increasing drug resistance and non-compliance to the therapy have been causing challenges to prevention and control of tuberculosis. ${ }^{6}$

Similarly, published research studies have been found 
related to compliance of TB treatment done in other districts such as Banke, Kailali, Bhaktapur, Palpa,Kathmandu, Okhaldhunga etc. But there is no recent published research study done in Kaski district related to compliance of TB treatment. In order to increase treatment compliance, it is necessary to identify all the factors that are associated with treatment compliance of TB treatment, Hence, the study is conducted to identify the factors associated with treatment compliance among tuberculosis patients.

\section{MATERIAL AND METHODS}

Descriptive cross-sectional design was used for the study. Pokhara valley was selected for the study. There were total 11 DOTS centre in Pokhara valley and all the centers were selected for the study. Purposive sampling technique was used for the study in which entire (census) population taking category first (Cat I) treatment that had completed the dose of 2 months (intensive phase) were selected for the study. Patients 18 years and above were selected.

Semi-structured interview schedule with a combination of close ended and open ended questions was developed. Total 29 questions were included. Interview schedule was divided into four parts: Part I comprised of demography related questions. Part II comprised of patient related questions. Part III comprised of health service related questions and Part IV comprised of social factor related questions. The content validity of tool was ascertained by consultation with peers, advisors, doctor of Regional Tuberculosis Centre and Tuberculosis department chief of district public health office, Kaski.

The instrument was prepared in English language and translated into Nepali language with the help of Nepali language expert to ensure the stability of the instrument. Pretesting of the instrument was done in $10 \%$ patients at Sisuwa PHC, Lekhnath municipality. On the basis of pretesting, the language of some questions was modified. Cronbach's alpha was used in order to evaluate the reliability of the instrument which was 0.76 .

After getting the research proposal approved by research committee of TU, IOM Pokhara Nursing campus and Institutional Review Board, Institute of Medicine, data collection was started. Before collecting the data, written request letter from Pokhara Nursing campus was submitted to district public health office, Kaski. Informed verbal consent was taken from the respondents before data collection. Data was collected from 142 respondents from $22^{\text {nd }}$ February to $21^{\text {st }}$ March 2015. The data was organized, coded and entered in Statistical Package for Social Science (SPSS) version 20. The data was analyzed by using descriptive statistics such as frequency, percentage, mean and standard deviation. To assess the association between different factors and compliance to TB treatment, Chi-square test was used at $5 \%$ level of significance.

\section{RESULTS}

Socio-demographic Information: Mean age of the respondents was $37.86(\mathrm{SD} \pm 16.37)$ years with minimum age of 18 and maximum of 85years. Almost two-third of them were male $(63.40 \%)$. Less than half $(42.30 \%)$ of the respondents were Janajatis and more than half $(58.50 \%)$ of respondents were married. Majority $(92.25 \%)$ of the respondents were literate. Twenty two percent of respondents were engaged in service. Almost equal (33.80\%), (33.10\%) and $(33.10 \%)$ of the respondents belong to low, medium and high economic status respectively.

Table 1: Distribution of Respondents according to Pattern of Compliance

\begin{tabular}{|l|l|l|l|}
\hline Pattern of Compliance & Number & Percentage & $\mathbf{( 9 5 \% C . I . )}$ \\
\hline Compliance & 134 & 94.37 & $(1.02,1.09)$ \\
\hline Non-compliance & 8 & 5.63 & \\
\hline
\end{tabular}

Mean \pm SD $1.06 \pm 0.23$

Table 1 shows that majority (94.37\%) of respondents are compliant and $(5.63 \%)$ are non-compliant. Mean value is 1.06 which lies between 1.02-1.09. Among non-compliant, majority $(75.00 \%)$ of respondents missed their medicine in intensive phase and $(25.00 \%)$ of respondents missed their medicine in continuation phase.

Table 2: Distribution of Non -compliant Respondents according to Reasons of Missing Medicine

\begin{tabular}{|l|c|c|}
\hline Reasons of Missing Medicine & Number & Percentage \\
\hline Confusion of staff & 1 & 12.5 \\
\hline Carelessness of patient & 2 & 25.0 \\
\hline Agitation by political parties & 2 & 25.0 \\
\hline Forgetfulness of patient & 2 & 25.0 \\
\hline Side effects & 1 & 12.5 \\
\hline
\end{tabular}

Table 2 reveals that reasons for missing medicine are due to confusion of staff $(12.50 \%)$, carelessness of patient $(25.00 \%)$, Agitation by political parties $(25.00 \%)$, forgetfulness of patient $(25.00 \%)$ and side effects of medicines $(12.50 \%)$.

Table 3: Association between Demographic factors and Treatment Compliance

\begin{tabular}{|c|c|c|c|c|}
\hline \multirow{2}{*}{$\begin{array}{c}\text { Demographic } \\
\text { Factors }\end{array}$} & \multicolumn{2}{|c|}{ Compliance Pattern } & \multirow[t]{2}{*}{$\chi^{2}$} & \multirow[t]{2}{*}{$p$ value } \\
\hline & $\begin{array}{c}\text { Compliance } \\
\text { №. }(\%)\end{array}$ & $\begin{array}{c}\text { Non-compliance } \\
\text { No. }(\%)\end{array}$ & & \\
\hline \multicolumn{5}{|l|}{ Age group } \\
\hline Adolescent & $4(66.67)$ & $2(33.33)$ & - & - \\
\hline Young Adult & $84(93.33)$ & $6(6.67)$ & & \\
\hline Middle Adult & $32(100)$ & $0(0.00)$ & & \\
\hline Elderly Adult & $14(100)$ & $0(0.00)$ & & \\
\hline \multicolumn{5}{|l|}{ Sex } \\
\hline Male & $87(96.67)$ & $3(3.33)$ & 1.408 & 0.235 \\
\hline Female & $47(90.38)$ & $5(9.62)$ & & \\
\hline
\end{tabular}




\begin{tabular}{|c|c|c|c|c|}
\hline \multicolumn{5}{|l|}{ Marital Status } \\
\hline Unmarried & $38(92.68)$ & $3(7.32)$ & - & - \\
\hline Married & $78(93.98)$ & $5(6.02)$ & & \\
\hline Widowed & $18(100)$ & $0(0.00)$ & & \\
\hline \multicolumn{5}{|l|}{$\begin{array}{l}\text { Educational } \\
\text { Status }\end{array}$} \\
\hline Illiterate & $11(100)$ & $0(0.00)$ & - & - \\
\hline$<\mathrm{SLC}$ & $82(94.25)$ & $5(5.75)$ & & \\
\hline$\geq \mathrm{SLC}$ & 41(93.18) & $3(6.82)$ & & \\
\hline \multicolumn{5}{|l|}{$\begin{array}{l}\text { Occupational } \\
\text { Status }\end{array}$} \\
\hline $\begin{array}{l}\text { Economically } \\
\text { active }\end{array}$ & $95(96.94)$ & $3(3.06)$ & 2.530 & 0.112 \\
\hline $\begin{array}{l}\text { Economically } \\
\text { inactive }\end{array}$ & $39(88.64)$ & $5(11.36)$ & & \\
\hline \multicolumn{5}{|l|}{$\begin{array}{l}\text { Economic } \\
\text { Status }\end{array}$} \\
\hline Low & $46(95.83)$ & $2(4.17)$ & 1.033 & 0.597 \\
\hline $\begin{array}{l}\text { Medium } \\
\text { High }\end{array}$ & $\begin{array}{l}43(91.49) \\
45(95.74)\end{array}$ & $\begin{array}{l}4(8.51) \\
2(4.26)\end{array}$ & & \\
\hline
\end{tabular}

Table 3 shows (100\%) compliance in middle adult and elderly adult. There is no significant association between treatment compliance and sex, occupation and economic status ( $\mathrm{p}>0.05)$.

Table 4: Association between Patient Related Factors and Treatment Compliance

\begin{tabular}{|l|l|l|l|l|}
\hline \multirow{2}{*}{ Factors } & \multicolumn{2}{c|}{ Compliance Pattern } & $\chi^{\mathbf{2}}$ & p value \\
\cline { 2 - 5 } & $\begin{array}{c}\text { Compliance } \\
\text { No. }(\%)\end{array}$ & $\begin{array}{c}\text { Non- } \\
\text { compliance } \\
\text { No. (\%) }\end{array}$ & & \\
\hline Knowledge & & & & \\
\hline Above average $(>10$ score $)$ & $128(94.81)$ & $7(5.19)$ & 0.32 & 0.850 \\
\hline Below average( $<10$ score) & $6(85.71)$ & $1(14.29)$ & & \\
\hline Side effects & & & & \\
\hline Yes & $55(96.49)$ & $2(3.51)$ & 0.279 & 0.597 \\
\hline No & $79(92.94)$ & $6(7.06)$ & & \\
\hline
\end{tabular}

Table 4 shows that there is no significant association between treatment compliance and knowledge of respondents and side effects of medicines ( $\mathrm{p}>0.05$ ).

Table 5: Association between Health Service Factors and Treatment Compliance

\begin{tabular}{|c|l|l|l|l|}
\hline \multirow{2}{*}{ Factors } & \multicolumn{2}{|c|}{ Compliance Pattern } & $\chi^{2}$ & $p$ value \\
\cline { 2 - 5 } & $\begin{array}{c}\text { Compliance } \\
\text { No. (\%) }\end{array}$ & $\begin{array}{c}\text { Non-compliance } \\
\text { No. }(\%)\end{array}$ & & \\
\hline Distance of DOTS Centre & & & & \\
\hline$\leq 5 \mathrm{~km}$ & $132(94.29)$ & $8(5.71)$ & - & - \\
\hline $6-10 \mathrm{~km}$ & $2(100.00)$ & $0(0.00)$ & & \\
\hline Travelling Time & & & & \\
\hline$\leq 15 \mathrm{~min}$ & $132(94.29)$ & $8(5.71)$ & - & - \\
\hline $16-20 \mathrm{~min}$ & $2(100.00)$ & $0(0.00)$ & & \\
\hline
\end{tabular}

\begin{tabular}{|c|l|l|l|l|}
\hline Transportation Cost & & & & \\
\hline Yes & $27(96.43)$ & $1(3.57)$ & 0.005 & 0.944 \\
\hline No & $107(93.86)$ & $7(6.14)$ & & \\
\hline $\begin{array}{l}\text { Opening Time } \\
\text { convenient }\end{array}$ & & & & \\
\hline Yes & $129(94.85)$ & $7(5.15)$ & 0.86 & 0.769 \\
\hline No & $5(83.33)$ & $1(16.67)$ & & \\
\hline Satisfaction of Service & & & & \\
\hline Yes & $129(94.85)$ & $7(5.15)$ & 0.86 & 0.769 \\
\hline No & $5(83.33)$ & $1(16.67)$ & & \\
\hline
\end{tabular}

Table 5 shows that $(100 \%)$ compliance is found in respondents who had to travel 6-10 km distance to DOTS centre. Similarly, (100\%) compliance is found in respondents who had to travel 16-20 minutes to DOTS centre. There is no significant association between treatment compliance and transportation cost to DOTS centre, convenience of DOTS centre opening time and patient satisfaction $(\mathrm{p}>0.05)$.

Table 6: Association between Social Factor and Treatment Compliance

\begin{tabular}{|l|l|l|l|l|}
\hline \multirow{2}{*}{ Factors } & \multicolumn{2}{|c|}{ Compliance Pattern } & $\chi^{2}$ & p value \\
\cline { 2 - 5 } & $\begin{array}{c}\text { Compliance } \\
\text { No. (\%) }\end{array}$ & $\begin{array}{c}\text { Non-compliance } \\
\text { No. (\%) }\end{array}$ & & \\
\hline Family Support & & & & \\
\hline Yes & $131(94.93)$ & $7(5.07)$ & 0.365 & 0.546 \\
\hline No & $3(75.00)$ & $1(25.00)$ & & \\
\hline
\end{tabular}

Table 6 shows that $(94.93 \%)$ of respondents who had got family support are compliant and only $1(25.00 \%)$ of respondents who had not got family support is non-compliant. The study found no significant association between family support and treatment compliance $(\mathrm{p}>0.05)$.

\section{DISCUSSION}

The study found that among 142 respondents, 135 (94.36\%) of respondents was compliant and $8(5.63 \%)$ was noncompliant. This study found higher compliance comparing to the study of Nepali and Paneru in Banke district which found that (57.00\%) compliant and (43.00\%) non-compliant patients. ${ }^{6}$ Similarly, majority $(75.00 \%)$ of non-compliant patients became non-compliant in intensive phase and $(25.00 \%)$ became non-compliant in continuation phase. This finding does not support the study conducted in Palpa which found that majority $(79.50 \%)$ missed their treatment in continuation phase. ${ }^{4}$

The study found that the reasons for non-compliance were carelessness of patient, confusion of staff, forgetfulness and Nepal Banda. This finding is different to the literature of Nepali and Paneru which stated that feeling of getting cure even before the course of DOTS and drinking habits were major causes of non-compliance. ${ }^{6}$ 
Compliance percentage was higher in middle adult and elderly adult comparative to young adult and adolescents. This finding does not support the study in Nepali and Paneru which found that compliance percentage higher in lower age group. ${ }^{4,69}$ Emotional maturity of patients of higher age group might cause this result in this study.

The study found no statistically significant association between sex of patients and treatment compliance. Similar finding was found in study of Palpa, Banke, Kathmandu and in South Africa. $4,6,7,8,9$

The study found no statistically significant association between occupational status of patients and treatment compliance. Similar finding was found in previous studies. ${ }^{4,8,9,10}$ Being people more conscious about their health, influence of health education might cause this result.

The study found no statistically significant association between socioeconomic status of patients and treatment compliance. This finding is consistent to the findings of Nepali and Paneru. ${ }^{6,7,9,10}$ Free supply of medicine and accessibility of DOTS centres near their home might cause this result.

Out of non-compliant patients, nobody missed their medicines due to being free of symptoms after some months of treatment. This finding does not support the findings of previous studies. Some of the studies such as in Palpa, Banke and Dladla in South Africa, found that non-compliance was associated with being free of symptoms after some months of treatment. ${ }^{4,6,11}$

In this study, all respondents $142(100 \%)$ said that they had received proper health education from the staffs of DOTS centre. Study of Shrestha, Bam and Chand found higher compliance in patients who had received health education than those who did not. ${ }^{8}$

\section{CONCLUSION}

Based on the findings, the study found no significant association of treatment compliance with demographic factors, patient related factors, health service factors and social factors. The study found satisfactory result that the compliance of patients was high i.e. majority $(94.37 \%)$ of the patients were compliant and (5.63\%) of respondents were non-compliant. Among non-compliant patients, most of them missed their medicine in intensive phase of treatment. The reasons for missing medicines were carelessness of patient, forgetfulness of patient, confusion of staff, side effects of medicines and agitation by political parties. The satisfactory result was the achievement of great effort of team of district public health office as well as of DOTS centres. Regular supervision and monitoring system from district public health office, availability of health education, provision of community based DOTS programme, accessibility of DOTS centre and good patient-healthcare provider relationship were very effective for promoting compliance. Patients who were compliant, were very conscious about their health and treatment. They had extreme fear of complications of missing medicines. Most of the patients were aware about relapse TB and Multidrug resistance (MDR) TB. Therefore, those patients had not missed their treatment.

\section{ACKNOWLEDGEMENT}

It is a sense of great honor and pride to place on record my sincere gratitude to Prof. Dr. Sarala Shrestha for her guidance, valuable suggestions and encouragement in the study. I would like to express my special thanks to Director of Regional Tuberculosis Centre, Dr. Mukunda Acharya, district public health officer of DPHO, Kaski, TB department chief, Basanta Bhattarai and all staffs of all DOTS centers of Pokhara valley for granting permission and providing necessary cooperation throughout the data collection period.

\section{REFERENCES}

1. World World Health Organization. Global tuberculosis report 2012. World Health Organization, 2012.

2. National Tuberculosis centre, Annual Report, National Tuberculosis Control Programme, Thimi, Nepal, 2012/2013. Retrieved from http://nepalntp.gov.np/theme/images/uploads/1395815121000000000Annual_TB_ report_2069-70.pdf.

3. Tessema B, Muche A, Bekele A, Reissig D, Emmrich F, Sack U. Treatment outcome of tuberculosis patients at Gondar University Teaching Hospital, Northwest Ethiopia. A five-year retrospective study. BMC public Health, 2009 Oct 4; 9(1):371.

4. Nepal AK, Shiyalap K, Sermsri S, Keiwkarnka B. Compliance with DOTS among tuberculosis patients under community based DOTS strategy in Palpa District, Nepal. International Journal of Infection and Microbiology, 2012 Oct $8 ; 1(1): 14-9$.

5. Banstola A. A Regional Workshop on Issues and threats regarding Tuberculosis Control in Nepal, 2010.retrieved from \https://www.ghdonline.org/ic/discussion/issues-and-threats-of-tuberculosis-in-nepal/

6. Nepali RB and Paneru DP. Compliance to Directly Observed Treatment Short-Course (DOTS) Chemotherapy 
among the patients of pulmonary tuberculosis in Banke district of Nepal. Journal of Health and Allied Sciences, 2013; 3(0):1.

7. Bam TS, Gunneberg C, Chamroonsawasdi K, Bam DS, Aalberg O, Kasland O, Shiyalap K, Srisorrachatr S. Factors affecting patient adherence to DOTS in urban Kathmandu, Nepal. The International Journal of Tuberculosis and Lung Disease, 2006 Mar 1; 10(3):270-6.

8. Shrestha SD, Bam TS, Chand KB. Factors Responsible for Non-compliance among Tuberculosis Patients in Kailali District, Nepal. Journal of Nepal Health Research Council, 2005 Dec 30.

9. Chani K. Factors affecting compliance to tuberculosis treatment in Andara Kavango region Namibia (Doctoral dissertation), 2010.

10. Adolphus I \& Fekadu A. Assessment of Defaulting from Directly Observed Treatment Short Course (DOTS) and its Determinants in Benin City, Nigeria. Journal of Tuberculosis Research, 2014: 2:30-39.

11. Dladla CN. Factors contributing to non-compliance to pulmonary tuberculosis treatment among patients in Waterberg District Limpopo Province (Doctoral dissertation), 2013. 